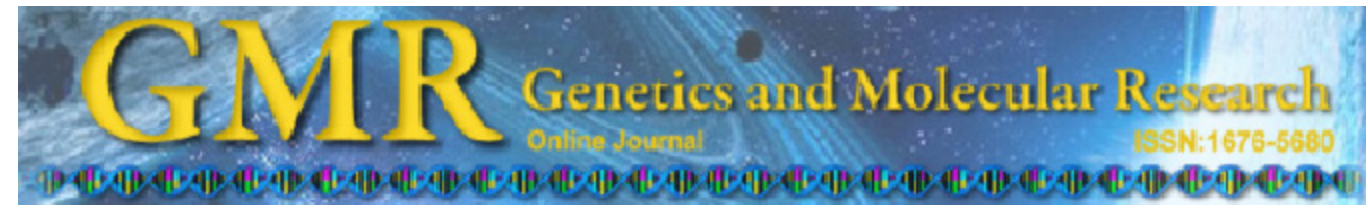

\title{
Differential expression of resistance to powdery mildew at the early stage of development in wheat line N0308
}

\author{
M.A. Alam ${ }^{1,2}$, W. Hongpo ${ }^{1}$, Z. Hong ${ }^{1}$ and W.Q. Ji ${ }^{1}$ \\ ${ }^{1}$ State Key Laboratory of Crop Stress Biology for Arid Areas, \\ College of Agronomy, Northwest A\&F University, Yangling, Shaanxi, China \\ ${ }^{2}$ Wheat Research Centre, Bangladesh Agricultural Research Institute, \\ Dinajpur, Bangladesh \\ Corresponding author: W.Q. Ji \\ E-mail: jiwanquan2008@126.com
}

Genet. Mol. Res. 13 (2): 4289-4301 (2014)

Received May 27, 2013

Accepted October 2, 2013

Published June 9, 2014

DOI http://dx.doi.org/10.4238/2014.June.9.15

\begin{abstract}
Powdery mildew, caused by Blumeria graminis f. sp tritici $(B g t)$ is one of the devastating diseases of wheat and causes yield losses in temperate wheat growing regions. A wheat line, N0308 with resistance to powdery mildew was used in this study. A suppression subtractive hybridization cDNA library was constructed from the wheat leaves inoculated by Bgt at the two-leaf stage. The differentially expressed genes in response to $B g t$ infection in wheat were identified, and a total of 175 positive clones from the library were sequenced, and 90 expressed sequence tags (ESTs) were subjected to clustering, BLAST alignment, functional annotation, and classification into different categories. By comparing the EST sequences among the SSH-cDNA libraries, we analyzed gene expression patterns of 7 ESTs associated with the resistance reaction of powdery mildew by using semi-quantitative reverse transcription-polymerase chain reaction. The expression of 5 genes (sulfatase, pathogenesis-related protein 17, betacarbonic anhydrase 2, thioredoxin h-like protein, and coronatineinsensitive) transcripts was induced, and the transcript levels of these
\end{abstract}


genes were the highest at $72 \mathrm{~h}$ after $B g t$ infection, while those of 2 genes (violaxanthin de-epoxidase and gag-pol-polyprotein) were the highest level at 12 and $18 \mathrm{~h}$ post-infection, respectively. These findings suggest that these genes are induced at an early stage of infection and are transcriptionally activated for the host defense response.

Key words: Expressed sequence tags; Wheat; Powdery mildew; Suppression subtraction hybridization

\section{INTRODUCTION}

Powdery mildew, caused by Blumeria graminis f. sp tritici (Bgt), is a wheat foliar disease that occurs in regions with maritime and semi-continental climates and causes serious yield losses. Although the use of fungicide can help control the powdery mildew, host resistance $(R)$ is rapidly becoming a primary method for control, particularly since the fungus is gaining increased tolerance to commonly used fungicides (Davidson et al., 2006). Qualitative (single gene) and quantitative (multiple genes) plant resistance is an important part of crop disease management (Jones, 2001). Plant defense mechanisms have been studied extensively in model systems, and these mechanisms may vary according to specific host-pathogen interactions (Alam et al., 2011).

Resistance of plant responses to pathogens are a focus of intensive research, because modern technologies offer the possibility of genetically engineering plants for broad-based, effective resistance in crop species. Resistance responses can be divided into a series of inter-related stages (Dangl and Jones, 2001; Veronese et al., 2003). Recognition of pathogen is the earliest step by the host plant that frequently involves interaction between $\mathrm{R}$ genes and pathogen avirulence genes that encode specific elicitors. An incompatible interaction results in the triggering of the defense responses through signaling pathways, including nitric oxide, reactive oxygen intermediates, jasmonic acid (JA), salicylic acid (SA), and ethylene. Signal transduction pathways activate a broad series of defense responses that remove the pathogen, such as hypersensitive response (HR); upregulation of phenylalanine ammonium lyase, a key enzyme in plant defense; deposition of cell wall reinforcing materials; and synthesis of a wide range of antimicrobial compounds, including pathogenesis-related (PR) proteins and phytoalexins (Veronese et al., 2003).

Subtractive suppression hybridization ( $\mathrm{SSH}$ ) is an effective method that can be used to isolate plant genes that are expressed in response to infection and disease development ( $\mathrm{Lu}$ et al., 2004). The SSH-cDNA library technique reduces the cloning of abundantly expressed genes that are commonly expressed in both plants (control and treated), thereby significantly enhancing the chances of cloning differentially expressed genes. The aim of this study was to construct a SSH-cDNA-library to identify and verify genes that are differentially expressed during an incompatible interaction after Bgt infection. By using this approach, we identified powdery mildew-responsive genes, classified them into functional groups, and disclosed the resistance mechanism against powdery mildew at global transcriptional level.

\section{MATERIAL AND METHODS}

\section{Materials}

Wheat germplasm N0308, a powdery mildew resistant line (Alam et al., 2013), was 
provided by the College of Agronomy, Northwest A\&F University. The race E09 of Bgt was used in the present study. N0308 seedlings showed incompatible reaction (infection type, 0) after infection with Bgt race E09.

\section{Powdery mildew inoculation}

The wheat seedlings of N0308 were planted in a greenhouse for 3 weeks, and then the seedlings were divided into 2 groups. One group of seedlings was inoculated with spores of E09 as a tester, and the other group was without inoculation and used as a driver. Inoculated wheat leaves were covered with transparent plastic bags for maintaining temperature and moisture. After inoculation, 3-4 leaves were cut at 0, 6, 12, 18, 24, 36, 48, and $72 \mathrm{~h}$ and placed in $5-\mathrm{mL}$ centrifuge tubes, immediately frozen in liquid nitrogen, and then stored at $-80^{\circ} \mathrm{C}$.

\section{SSH-cDNA library construction}

Total RNA, for each tester and driver sample, was extracted from the plant leaf material by using Invitrogen Trizol reagent. Trace DNA was removed with DNase I. Doublestranded cDNA was produced from approximately $5 \mathrm{mg}$ total RNA. SSH was performed using cDNA from inoculated and non-inoculated leaves by using polymerase chain reaction (PCR)select cDNA Subtraction Kit (Clontech, Palo Alto, CA, USA).

The products from 2 rounds of SSH were used for 2 nested PCR amplifications, and the amplified products were purified and ligated into the pGEM $^{\circledR}-\mathrm{T}$ easy vector (Promega, USA). The ligation products were transformed into Escherichia coli DH5 $\alpha$ competent cells. The transformed cells were selected by ampicillin $(100 \mu \mathrm{g} / \mathrm{mL})$ on X-gal/isopropyl- $\beta$ D-thiogalactopyranoside plates. The white colonies were selected for PCR by using Sp6 and $\mathrm{T} 7$ promoter sequences as primers. The positive clones were screened and tested for the size of inserts.

\section{Sequencing and bioinformatic analysis}

The plasmid DNA was extracted from positive clones and sequenced by AuGCT DNA-SYN Biotechnology Lab., Beijing, China. After the vector, primer, adaptor sequences and sequences less than $80 \mathrm{bp}$ were removed, the CAP3 software was used to assemble these sequences into contig. The resultant sequences were then submitted to GenBank. The expressed sequence tag (EST) sequences obtained were compared to GenBank dbEST database and non-redundant protein database for a homology search, and analyses were conducted using the BLAST program of the National Center of Biotechnology Information (NCBI; http:// www.ncbi.nlm.nih.gov). The evaluation rule of significant sequences was E-value less than $10^{-5}$ and identities more than $40 \%$ ( $\mathrm{Li}$ et al., 2004). The function of ESTs was classified according to the method of Bevan et al. (1998).

\section{Semi-quantitative reverse transcriptase (RT)-PCR}

The gene-specific primers were used for semi-quantitative RT-PCRs. The primers were designed on the basis of the selected ESTs by using Primer 3.0; synthesized by AuGCT 
DNA-SYN Biotechnology Lab., China; and are listed in Table 1. RT-PCR was performed using PrimeScript ${ }^{\mathrm{TM}} 1$ st strand cDNA Synthesis Kit (TaKaRa Biotechnology Co., Dalian City, China). The amount of cDNA template was normalized using $\alpha$-tublin as an internal reference during PCR amplification (Nicot et al., 2005). The PCR analyses were performed in a total volume of $20 \mu \mathrm{L}$ containing $0.4 \mathrm{mM}$ dNTPs, $0.2 \mu \mathrm{L}$ Taq DNA polymerase (TakaRa, Dalian, China), $0.5 \mu \mathrm{M}$ of each primer, $25 \mathrm{ng}$ cDNA, and $2 \mu \mathrm{L} 10 \mathrm{X}$ cDNA PCR buffer. After the PCR amplification performances were compared in 35,38 , and 42 cycles, the PCR cycles were selected as follows: one cycle of $95^{\circ} \mathrm{C}$ for $2 \mathrm{~min} ; 35$ cycles of $92^{\circ} \mathrm{C}$ for $30 \mathrm{~s}, 50^{\circ}-60^{\circ} \mathrm{C}$ (depending on primer) for $50 \mathrm{~s}$, and $72^{\circ} \mathrm{C}$ for $30 \mathrm{~s}$; and a final extension at $72^{\circ} \mathrm{C}$ for $5 \mathrm{~min}$. The amplification products and molecular weight markers were separated by agarose gel electrophoresis and visualized using a BioRad gel documentation system (Bio-Rad Laboratories, Hercules, CA, USA).

\begin{tabular}{|c|c|c|}
\hline GenBank accession No. & Amplified gene & 5'-3' RT-PCR \\
\hline $\mathrm{JZ124080}$ & Violaxanthin de-epoxidase (VDE) & $\begin{array}{l}\text { F: GATCCCTCACAACCAGCAAT } \\
\text { R: AAGTCCTGCCCTACGCTTTT }\end{array}$ \\
\hline JZ124084 & Sulfatase & $\begin{array}{l}\text { F: GTCCCGTCTGTGCTTTTCAT } \\
\text { R: GTGCTGGCGATCCAGTCC }\end{array}$ \\
\hline JZ124106 & Gag-pol-polyprotein (GPP) & $\begin{array}{l}\text { F: CATTGGAGCAAGAACAAGCA } \\
\text { R: AAATAGCCTCGGGACGAAAT }\end{array}$ \\
\hline JZ124128 & Pathogenesis-related protein 17 (PR-17) & $\begin{array}{l}\text { F: GGACTACTGCGACTCCCTCA } \\
\text { R: AACAAACTGCATGCATCGTC }\end{array}$ \\
\hline JZ124147 & Betacarbonic anhydrase 2 ( $\beta$-CAs2) & $\begin{array}{l}\text { F: CCTTCCTTCACCCTTTCCTC } \\
\text { R: CTGGGTCTCACTTGGGAAGA }\end{array}$ \\
\hline JZ124117 & Coronatine-insensitive (COI) & $\begin{array}{l}\text { F: AGGGAATTTCCGGTGGAG } \\
\text { R: TTCAAGGAGCCAAGGCACTA }\end{array}$ \\
\hline JZ124096 & $\begin{array}{l}\text { Thioredoxin h-like protein (Trxh) } \\
\alpha \text {-tublin }\end{array}$ & $\begin{array}{l}\text { F: CATGGTTCAACTGCCATCAC } \\
\text { R: TGTTTATGCCGAGATGTCCA } \\
\text { F: CCAAGTTCTGGGAGGTGATCTG } \\
\text { R: TGTAGTAGACGTTGATGCGCTC }\end{array}$ \\
\hline
\end{tabular}

\section{RESULTS}

\section{SSH-cDNA library construction}

Total RNA for SSH analyses was extracted using mixed RNA samples isolated from N0308 leaves at 24, 48, and $72 \mathrm{~h}$ after inoculation, while RNA for gene expression analysis was obtained from all sampling points. DNase I treatment was applied to remove contaminating genomic DNA.

\section{Analysis of SSH library}

The second-round PCR amplification products were ligated to $\mathrm{pGEM}^{\circledR}-\mathrm{T}$ easy vector and then transferred into DH5 $\alpha$ by heat shock. PCR analysis of white colonies containing inserts in the $\mathrm{pGEM}^{\circledR}$-T easy vector showed that the size of the inserted fragment ranged from 200 to $1000 \mathrm{bp}$ (Figure 1). About 350 clones were chosen randomly from SSH-cDNA library. A total of 175 positive clones from the library were subjected to sequencing. After the redundant and repeated sequences and those shorter than $80 \mathrm{bp}$ were removed, 90 high-quality EST 
sequences were obtained. These sequences were submitted to NCBI with the GenBank accessions of JZ124067 to JZ124156 and dbEST-Id from 77682937 to 77683026.

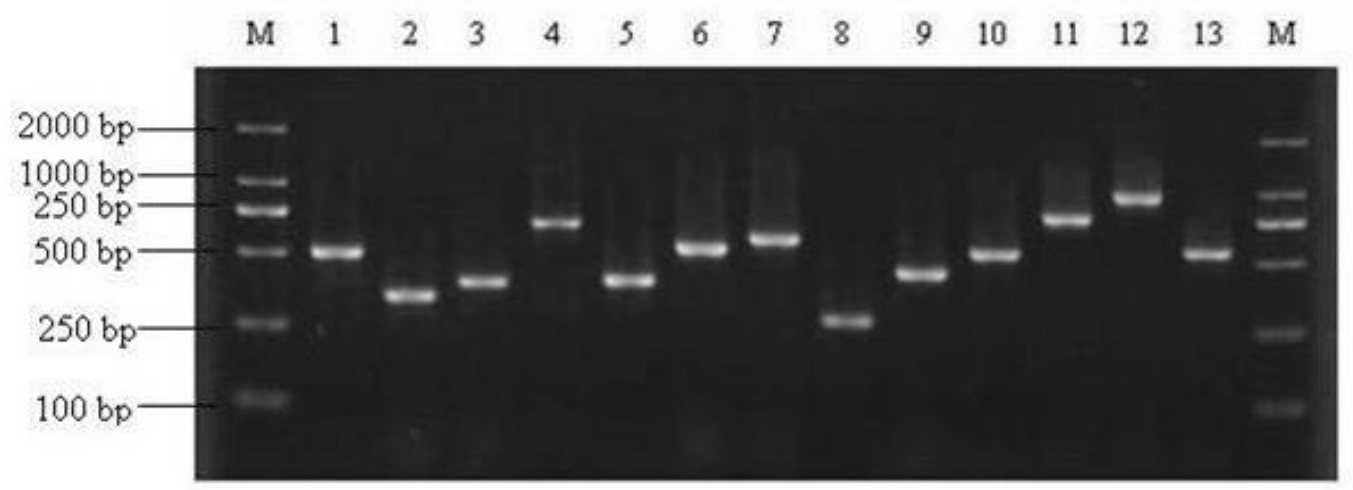

Figure 1. Identification of inserted fragments from the subtracted cDNA library. Lanes 1 to $13=13$ randomly selected clones; lane $M=$ DL 2000 marker.

\section{EST alignment}

BlastX was used to perform a homology search against the GenBank nonredundant protein database. In all, 47 ESTs showed high homology to the known proteins, accounting for $52.2 \%$ of the 90 ESTs, most of which were from the cDNA library derived from Triticum aestivum, Brachypodium distachyon, Oryza sativa, Hordeum vulgare, Arabidopsis thaliana, Zea mays, and other crops under biotic or abiotic stresses (Table 2).

The putative genes were categorized by biological process according to predicted gene ontology. Nine major ontological groups were designated as follows: defense and stress response, metabolism, energy, protein synthesis and storage proteins, signal transduction, transcription, transporter, immune system, and cell growth and division. The group with the largest number of genes was defense and stress response (22\%), followed by transcription $(17 \%)$ and energy $(13 \%)$. Metabolism (11\%), signal transduction (9\%), protein synthesis and storage proteins $(6 \%)$, transporter $(6 \%)$, and cell growth and division $(6 \%)$ were the next abundant group. The lesser-affected category was immune system (4\%; Figure 2). In addition, there were $6 \%$ ESTs with unknown functions.

Disease resistance-related genes have been discovered in the libraries constructed previously, such as senescence-associated proteins, peroxidase, wound-induced proteins, stressinduced proteins, iron deficiency-induced proteins, and guanosine triphosphate-binding proteins (Luo et al., 2002; Liu et al., 2006; Yu et al., 2007; Wu et al., 2010; Zeng et al., 2010). In this study, ESTs were discovered for the first time that displayed high similarity to the genes encoding RCD1 protein, mutator protein, violaxanthin de-epoxidase (VDE), cAMP- binding protein, coronatine-insensitive (COI), and lipopolysaccharide biosynthesis proteins.

\section{Semi-quantitative RT-PCR and real-time PCR of resistance-related gene expression}

On the basis of the results of the BLAST search analysis, we selected 7 ESTs with 
M.A. Alam et al.

4294

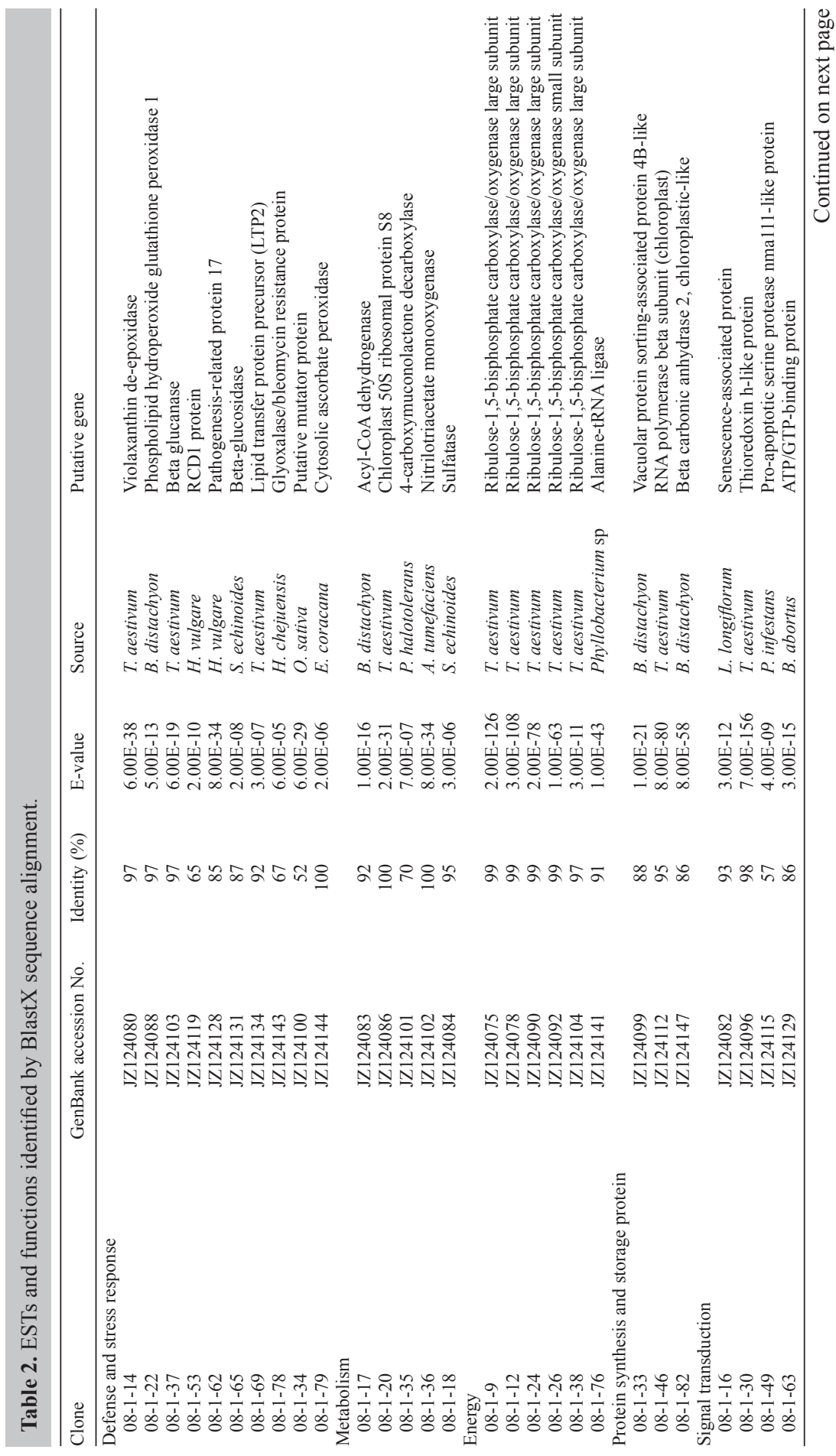




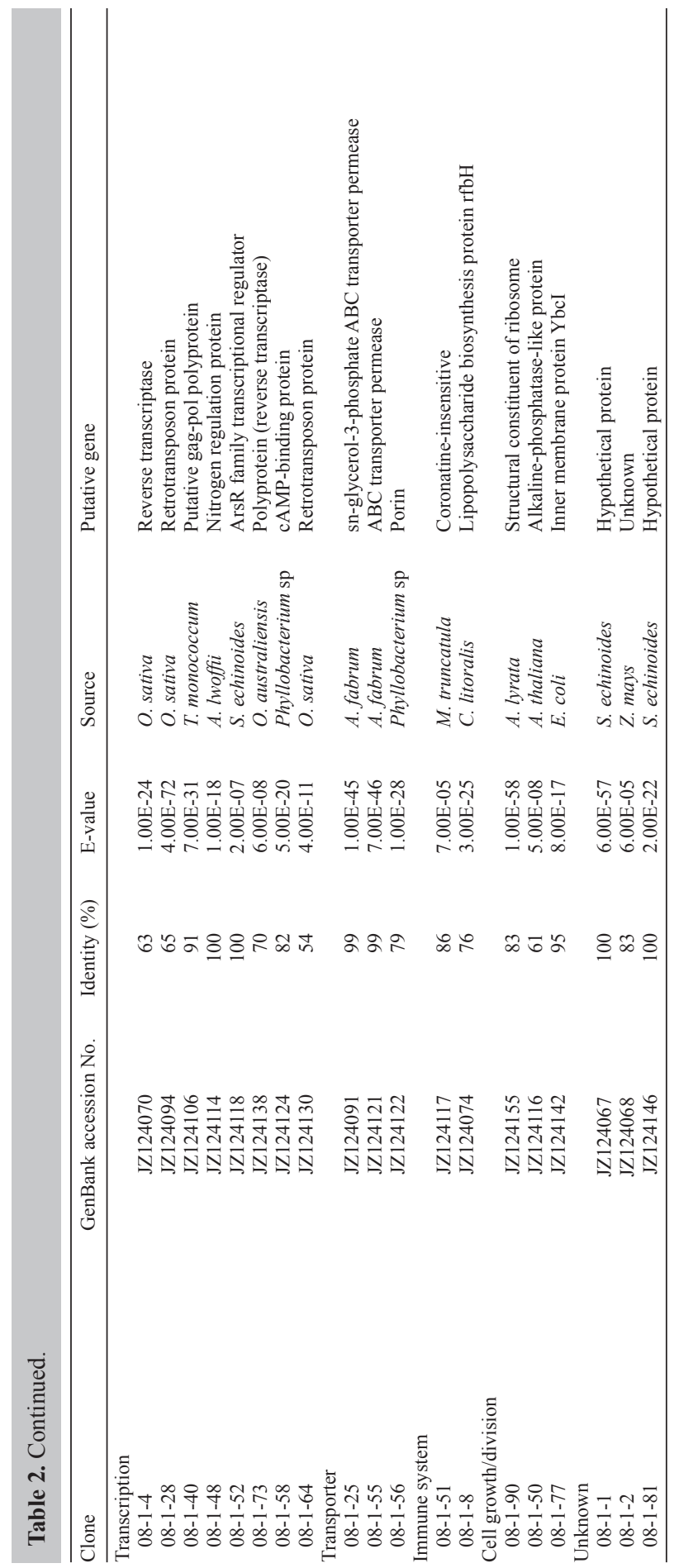


high homologies to genes inoculated by Bgt race E09 for expression analysis. They were VDE, sulfatas, gag-pol-polyprotein (GPP), pathogenesis-related protein 17 (PR-17), betacarbonic anhydrase 2 ( $\beta$-CAs2), thioredoxin h-like protein (Trxh), and COI. After the preexperiment on cycling times was perfoprmed and the amount of the cDNA template was normalized using the $\alpha$-tublin gene as an internal reference, a 35-cycle PCR was adopted for all analyses.

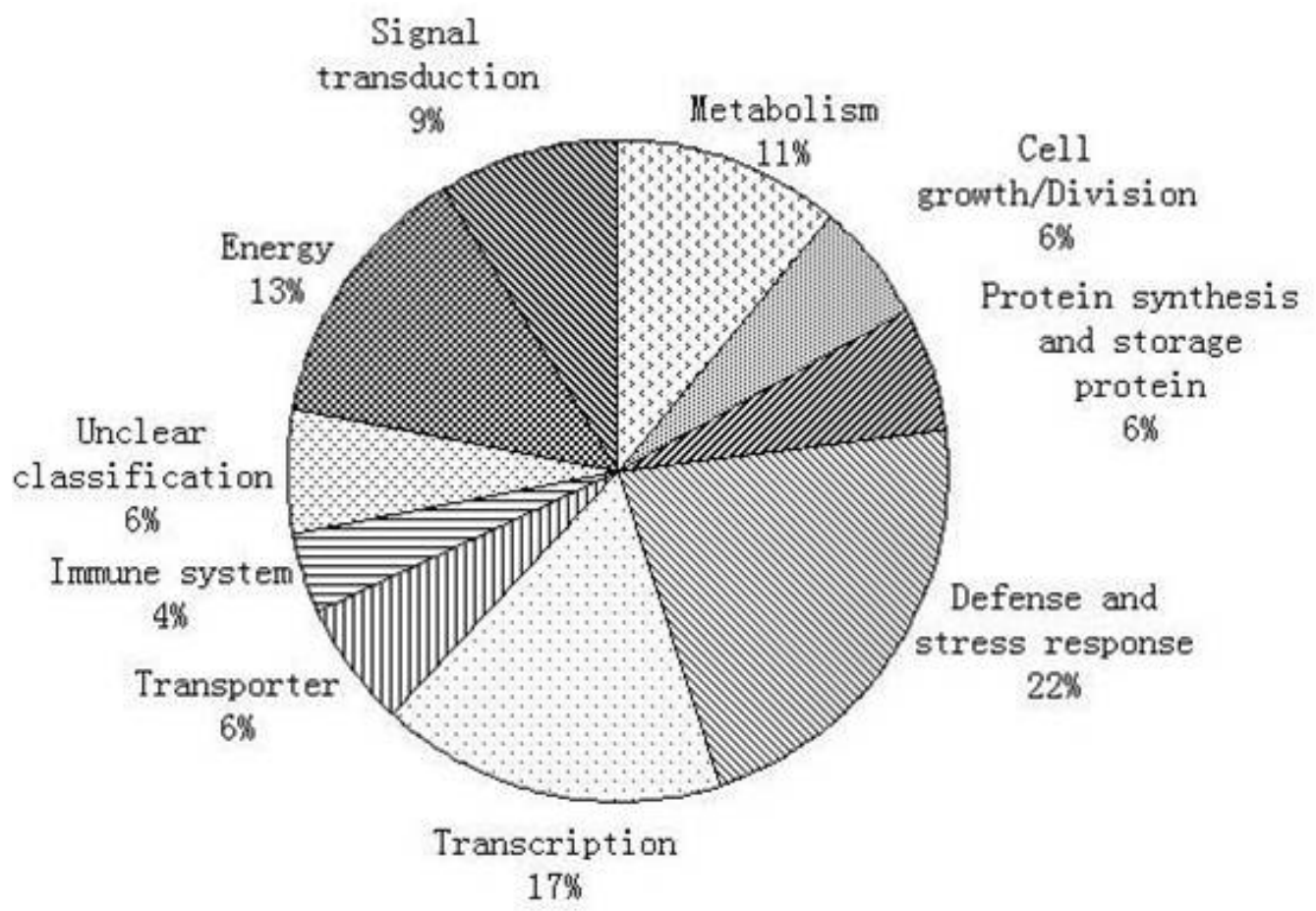

Figure 2. Functional category and the ratio of expressed sequence tags based on the results of BlastX.

Semi-quantitative RT-PCR results (Figures 3 and 4) showed that, after Bgt inoculation, GPP was expressed to the highest level at 12 hours post-inoculation (hpi), and VDE was expressed highly at $18 \mathrm{hpi}$ and thereafter showed decreased expression from $24 \mathrm{hpi}$ but was not significant compared to the expression level at any other time point. The expression level increased significantly for COI, Trxh, and PR-17 at 72 hpi compared with that in non-inoculated resistant plants. The $\beta$-CAs 2 was expressed to the highest level at $72 \mathrm{hpi}$, and no expression was found at other time points. These results confirmed that these ESTs were differentially expressed in wheat in response to Bgt infection. Sulfatase showed the highest expression at 72 hpi but insignificant with that at other time points. All the 7 candidate genes were found to be expressed at the basal level before $B g t$ inoculation, whereas 5 (sulfatase, PR-17, $\beta$-CAs2, Trxh, and COI) were expressed at the maximum level at 72 hpi. GPP and VDE genes were expressed at the highest level at 12 and 18 hpi, respectively. 


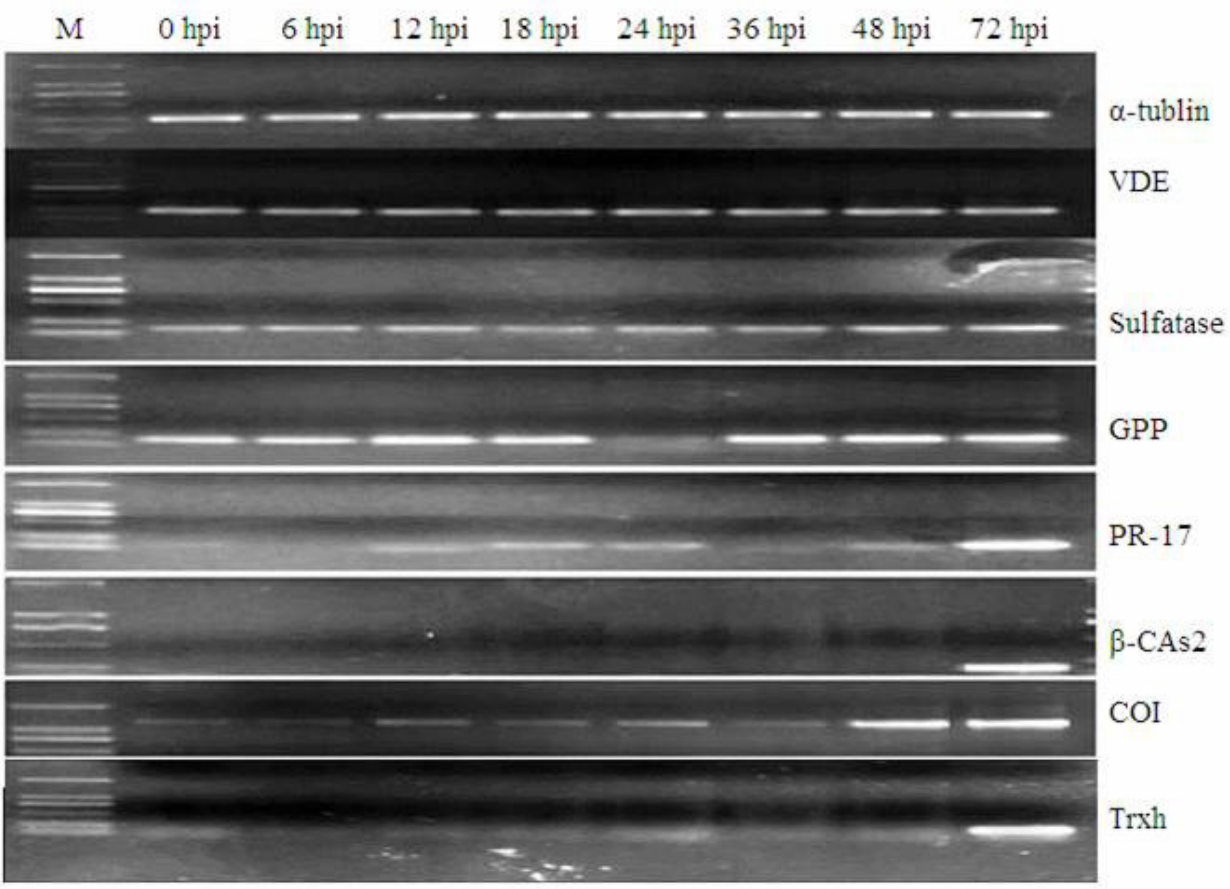

Figure 3. Semi-quantitative RT-PCR analysis of selected genes at different time points after Bgt infection.

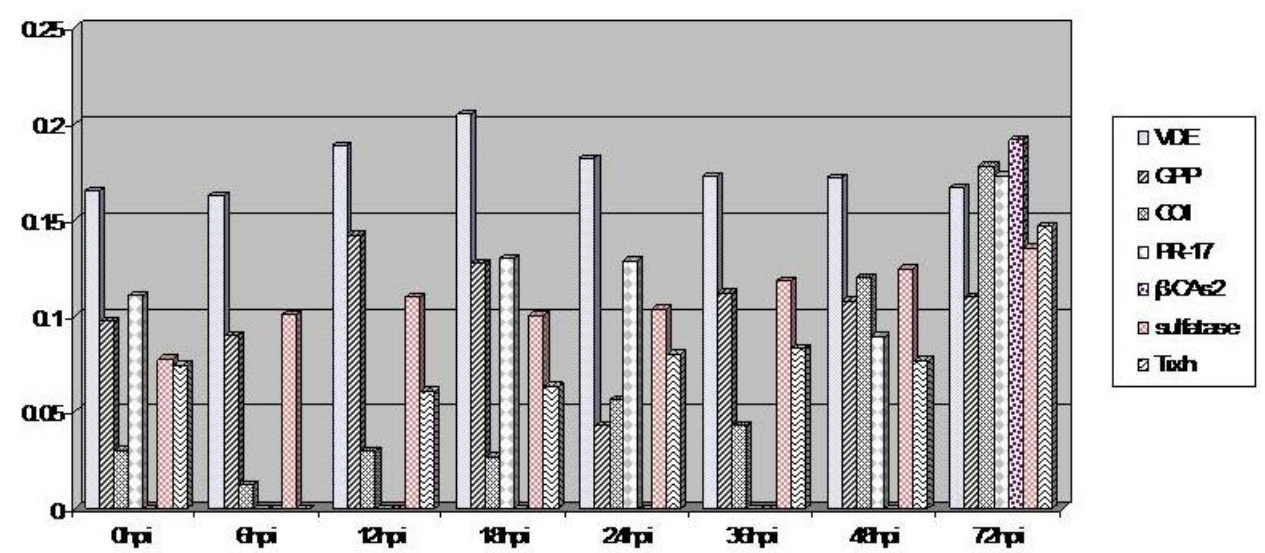

Figure 4. Semi-quantitative RT-PCR analysis of the expression patterns of candidate genes at different time points.

These results suggested that the 7 genes were transcribed at an early stage of $B g t$ inoculation, but the expression level of VDE was higher than that of the other expressed genes, suggesting that this gene may control defense mechanism in host plants via a different regulatory system. 


\section{DISCUSSION}

SSH technology is a valuable tool for constructing subtracted cDNA libraries generated from specific conditions and for analyzing the involvement of metabolic genes at a genomic level. A SSH-cDNA library was constructed using the same amount of mixed total RNA, collected from wheat line N0308 leaves at 24, 48, and $72 \mathrm{~h}$ after Bgt race E09 inoculation. Genes associated with several biological processes were expressed after $B g t$ inoculation in the resistance line, including carbohydrate metabolism, nitrogen assimilation, biosynthesis of secondary metabolites, glycolysis, lipid metabolism, and hormone production. Induction of these genes is consistent with the findings of other studies on gene expression during host-pathogen interactions (Luo et al., 2002; Wu et al., 2010) and is indicative of a shift in metabolic processes towards synthesis of defense-related compounds (Shigaki and Bhattacharyya, 2000).

Among the genes with known protein functions, those involved in energy and basic metabolism, as well as defense and stress response, were highly expressed. In this study, the frequency of these 2 classes of genes was 24 and $22 \%$, respectively. In the relevant libraries in previous studies, the percentage of these 2 classes of genes were 29.2 and $13.3 \%, 53$ and 26\% and 40 and 17.1\%, respectively (Wang et al., 2008; Wu et al., 2010; Zeng et al., 2010). The high expression of genes related to energy and basic metabolism reflects the complex photoautotrophic metabolism of plants (Bevan et al., 1998). This result indicates that plants increase their metabolism for disease resistance when they are infected by pathogens or other infectious factors (Ingram and Bartels, 1996; Wang et al., 2008).

In the incompatible interactions between wheat and Bgt or Blumeria graminis f. sp hordei (Bgh), the expression of beta-1,3-glucanase, pathogenesis-related protein 17 (HvPR-17 and HvPR-17b), peroxidase, glutathione peroxidase, and ubiquitin-protein ligase transcripts were highly induced at an early stage of infection (Christensen et al., 2002; Luo et al., 2002; Wu et al., 2010; Zeng et al., 2010). In this study, the transcription of genes VDE, sulfatase, GPP, PR-17, $\beta$-CAs2, Trxh, and COI was upregulated after Bgt E09 infection. The upregulation of these genes might be associated with an enhanced defense response.

Proteins associated with defense and stress response were the largest proportion $(22 \%)$. These proteins included abiotic stress proteins and PR proteins such as $\beta$-glucanase, $\beta$-glucosidase, glyoxalase, and lipid transfer protein (LTP2). LTP2 plays important roles in lipid transport, plant defense responses, and cuticle formation (Cheng et al., 2004). $\beta$-glucanases along with PR-2 is rapidly triggered and accumulates in response to pathogen attack, elicitor treatment, and hormonal responses (Leubner-Metzger and Meins, 1999). $\beta$-glucanases are important fungal cell wall components and part of hypersensitive response to pathogen infection. The combination of $\beta$-1,3-glucanases with chitinase can be substantially more effective in degrading fungal cell walls (Broekaert et al., 2000). $\beta$-1,3-glucanases may also act indirectly by releasing elicitors from fungal cell walls, which can significantly stimulate phytoalexin accumulation in host plants. The glyoxalase system has been proposed to be involved in various functions such as cell division and proliferation regulation, microtubule assembly, and protection against oxoaldehyde toxicity (Thornalley, 1990). Singla-Pareek et al. (2003) genetically engineered the glyoxalase pathway leading to enhanced salinity tolerance in tobacco. Phospholipid hydroperoxide glutathione peroxidase protects cells against membrane lipid peroxidation and cell death. Radical-induced cell death1 (RCD1) protein is hypersensitive to apoplastic superoxide and ozone; more resistant to chloroplastic superoxide formation; exhibits reduced sensitivity to abscisic acid, ethylene, and methyl jasmonate; and leads to altered 
expression of several hormonally regulated genes (Ahlfors et al., 2004). RCD1 could act as an integrative node in hormonal signaling and in the regulation of several stress-responsive genes such as those activated during salt, cold, and drought stress (Ahlfors et al., 2004).

Many PRs were first characterized in tobacco; NtPRp 27 is constitutively expressed in tobacco roots but can be induced by tobacco mosaic virus, wounding, drought, and by the application of ethylene, methyl jasmonate, SA, and abscisic acid (Okushima et al., 2000). Recently NtPRp 27 became the prototype for the new PR family PR-17. Accumulation of mRNA encoding PR-17 proteins has been reported after benzothiadiazole treatment, inoculation with Erysiphe graminis f. sp tritici in wheat (Gorlach et al., 1996), and inoculation with Bgh in barley (Christensen et al., 2002). In this study, PR-17 was found to be upregulated at $72 \mathrm{hpi}$ after $B g t$ inoculation. Therefore, it is a Bgt-inducible gene. Christensen et al. (2002) also reported that PR-17 (HvPR-17a and HvPR-17b) was upregulated at $72 \mathrm{hpi}$ after powdery mildew (Bgh) infection in barley. Similarly, Wu et al. (2010) reported that PR gene was expressed highly at 72 hpi after powdery mildew infection in a resistant wheat cultivar.

The COI protein is involved in various functions, including defense response to fungus, bacteria, insect, and response to red light and heat. This protein is a jasmonic receptor. Jasmonates play many diverse roles in plant defense and development. COI1, an F-box protein essential for all jasmonate responses, interacts with multiple proteins to form the E3 ubiquitin ligase complex and recruits jasmonate ZIM-domain proteins for degradation via the $26 \mathrm{~S}$ proteasome (Yan et al., 2009). Jasmonic receptor is involved in the regulation of plant gene expression during plant-pathogen interactions with Pseudomonas syringae and Alternaria brassicicola (van Wees et al., 2003). VDE catalyzes the de-epoxidation of violaxanthin to antheraxanthin and zeaxanthin in the xanthophyll cycle (Rockholm and Yamamoto, 1996). It is also known to form a part of a conserved system in higher plants that dissipates excess energy as heat in the light-harvesting complexes of photosystem II, thus protecting them from photo-inhibitory damage.

The ESTs related to energy and metabolism were expressed in the largest proportion (24\%), including ribulose-1,5-bisphosphate carboxylase/oxygenase, acyl-coA dehydrogenease, and sulfage, and ribulose-1,5-bisphosphate carboxylase/oxygenase (RubisCO) showed the highest occurrence frequency. RubisCO is the key enzyme of the Calvin-Benson-Basham cycle and catalyzes the first step in which $\mathrm{CO}_{2}$ is reductively assimilated into organic carbon. It is also a bifunctional enzyme that controls the reduction of $\mathrm{CO}_{2}$ and oxygenolysis of ribulose-1,5-bisphophate. Plants are able to fix large amounts of carbon due to the occurrence of RubisCO and produce all primary products linked to the function of this enzyme. Further, it is a well-studied enzyme because of its extensive agricultural and environmental significance (Selesi et al., 2005).

After the pathogen is recognized, several signal transduction cascades can be activated, involving secondary signal molecules such as SA, JA, and ethylene (Zhao and Qi, 2008). Signal transduction-related constituents accounted for $9 \%$ of the total genes in our study. Senescenceassociated genes and Trxh are the main components of signal transduction pathways in eukaryotes. Senescence-associated genes are induced in response to diseases caused by fungi, bacteria, and viruses that trigger an HR or during infections caused by fungi and bacteria (Espinoza et al., 2007). Some senescence-associated genes encode defense-associated related proteins (e.g., PR proteins) that are induced during the HR against avirulent pathogens (Quirino et al., 2000). Infection of plants by bacteria or fungi also induces genes that are expressed at high levels during senescence. Trxh is involved in multiple processes, and its best documented function is 
its implication in reserve breakdown that sustains early seedling growth of germinating cereal seeds (Wong et al., 2002). These proteins are electron donors in several enzymes involved in the protection against oxidative stress, such as peroxiredoxin, methionine sulfoxide reductase, and glutathione reductase (Jung et al., 2002; Gelhaye et al., 2003).

In conclusion, our results suggest that the immune-resistant wheat variety triggers defense mechanisms after fungal infection to strengthen its resistance to disease by increasing the expression of defense-associated genes. These genes are associated with resistance to powdery mildew in wheat, but the regulation of their expression might be complex. Further characterization and functional analysis of the genes generated from the library will facilitate the understanding of the defense mechanisms in wheat to Bgt infection.

\section{ACKNOWLEDGMENTS}

Research supported by the China Scholarship Council (CSC) and "13115” Program of Shaanxi Province, China (\#2008ZDKG-07).

\section{REFERENCES}

Ahlfors R, Lang S, Overmyer K, Jaspers P, et al. (2004). Arabidopsis RADICAL-INDUCED CELL DEATH1 belongs to the WWE protein-protein interaction domain protein family and modulates abscisic acid, ethylene, and methyl jasmonate responses. Plant Cell 16: 1925-1937.

Alam MA, Xue F, Wang CY and Ji WQ (2011). Powdery mildew resistance genes in wheat: identification and genetic analysis. J. Mol. Biol. Res. 1: 20-39.

Alam MA, Xue F, Ali M, Wang CY, et al. (2013). Identification and molecular mapping of powdery mildew resistance gene PmG25 in common wheat originated from wild emmer (Triticum turgidum var. dicoccoides). Pak. J. Bot. 45: 203-208.

Bevan M, Bancroft I, Bent E, Love K, et al. (1998). Analysis of $1.9 \mathrm{Mb}$ of contiguous sequence from chromosome 4 of Arabidopsis thaliana. Nature 391: 485-488.

Broekaert WF, Terras FR and Cammue BP (2000). Induced and Pre-Formed Antimicrobial Proteins. In: Mechanisms of Resistance to Plant Diseases (Slusarenko AJ, Fraser RS and van Loon LC, eds.). Kluwer Academic Publishers, Boston, 371-477.

Cheng CS, Samuel D, Liu YJ, Shyu JC, et al. (2004). Binding mechanism of nonspecific lipid transfer proteins and their role in plant defense. Biochemistry 43: 13628-13636.

Christensen AB, Cho BH, Naesby M, Gregersen PL, et al. (2002). The molecular characterization of two barley proteins establishes the novel PR-17 family of pathogenesis-related proteins. Mol. Plant Pathol. 3: 135-144.

Dangl JL and Jones JD (2001). Plant pathogens and integrated defence responses to infection. Nature 411: 826-833.

Davidson RM, Hanson LE, France GD and Panella L (2006). Analysis of $\beta$-tubulin gene fragments from benzimidazolesensitive and tolerant Cercospora beticola. J. Phytopathol. 154: 321-328.

Espinoza C, Medina C, Somerville S and Arce-Johnson P (2007). Senescence-associated genes induced during compatible viral interactions with grapevine and Arabidopsis. J. Exp. Bot. 58: 3197-3212.

Gelhaye E, Rouhier N and Jacquot JP (2003). Evidence for a subgroup of thioredoxin h that requires GSH/Grx for its reduction. FEBS Lett. 555: 443-448.

Gorlach J, Volrath S, Knauf-Beiter G, Hengy G, et al. (1996). Benzothiadiazole, a novel class of inducers of systemic acquired resistance, activates gene expression and disease resistance in wheat. Plant Cell 8: 629-643.

Ingram J and Bartels D (1996). The molecular basis of dehydration tolerance in plants. Annu. Rev. Plant Physiol. Plant Mol. Biol. 47: 377-403.

Jones JD (2001). Putting knowledge of plant disease resistance genes to work. Curr. Opin. Plant Biol. 4: 281-287.

Jung BG, Lee KO, Lee SS, Chi YH, et al. (2002). A Chinese cabbage cDNA with high sequence identity to phospholipid hydroperoxide glutathione peroxidases encodes a novel isoform of thioredoxin-dependent peroxidase. J. Biol. Chem. 277: 12572-12578.

Leubner-Metzger G and Meins FJ (1999). Functions and Regulation of Plant $\beta$-1,3-glucanases (PR-2). In: PathogenesisRelated Proteins in Plants (Datta SK, Muth-Ukrishnan S, eds.). CRC Press, Boca Raton, 49-76. 
Li R, Rimmer R, Buchwaldt L, Sharpe AG, et al. (2004). Interaction of Sclerotinia sclerotiorum with a resistant Brassica napus cultivar: expressed sequence tag analysis identifies genes associated with fungal pathogenesis. Fungal Genet. Biol. 41: 735-753.

Liu TM, Hu YG, Zhang H, Song GQ, et al. (2006). Puccinia striiformis west-induced gene expression of wheat germplasm with stripe rust resistance. Acta Bot. Boreal.-Occident. Sin. 26: 521-526.

Lu G, Jantasuriyarat C, Zhou B and Wang GL (2004). Isolation and characterization of novel defense response genes involved in compatible and incompatible interactions between rice and Magnaporthe grisea. Theor. Appl. Genet. 108: 525-534.

Luo M, Kong XY, Huo NX, Zhou RH, et al. (2002). Analysis of gene resistant to powdery mildew by suppression subtractive hybridization. Chin. Sci. Bull. 47: 1237-1241.

Nicot N, Hausman JF, Hoffmann L and Evers D (2005). Housekeeping gene selection for real-time RT-PCR normalization in potato during biotic and abiotic stress. J. Exp. Bot. 56: 2907-2914.

Okushima Y, Koizumi N, Kusano T and Sano H (2000). Secreted proteins of tobacco cultured BY2 cells: identification of a new member of pathogenesis-related proteins. Plant Mol. Biol. 42: 479-488.

Quirino BF, Noh YS, Himelblau E and Amasino RM (2000). Molecular aspects of leaf senescence. Trends Plant Sci. 5: 278-282.

Rockholm DC and Yamamoto HY (1996). Violaxanthin de-epoxidase. Plant Physiol. 110: 697-703.

Selesi D, Schmid M and Hartmann A (2005). Diversity of green-like and red-like ribulose-1,5-bisphosphate carboxylase/ oxygenase large-subunit genes (cbbL) in differently managed agricultural soils. Appl. Environ. Microbiol. 71: 175-184.

Shigaki T and Bhattacharyya MK (2000). Decreased inositol 1,4,5-trisphosphate content in pathogen-challenged soybean cells. Mol. Plant Microbe Interact. 13: 563-567.

Singla-Pareek SL, Reddy MK and Sopory SK (2003). Genetic engineering of the glyoxalase pathway in tobacco leads to enhanced salinity tolerance. Proc. Natl. Acad. Sci. U. S. A. 100: 14672-14677.

Thornalley PJ (1990). The glyoxalase system: new developments towards functional characterization of a metabolic pathway fundamental to biological life. Biochem. J. 269: 1-11.

van Wees SC, Chang HS, Zhu T and Glazebrook J (2003). Characterization of the early response of Arabidopsis to Alternaria brassicicola infection using expression profiling. Plant Physiol. 132: 606-617.

Veronese P, Ruiz MT, Coca MA, Hernandez-Lopez A, et al. (2003). In defense against pathogens. Both plant sentinels and foot soldiers need to know the enemy. Plant Physiol. 131: 1580-1590.

Wang YF, Qu ZP, Zhang YH, Ma JB, et al. (2008). Construction of a cDNA Library and analysis of expressed sequence tags in association with the incompatible interaction between wheat and Puccinia striiformis. Sci. Agric. Sin. 4: 3376-3381.

Wong JH, Kim YB, Ren PH, Cai N, et al. (2002). Transgenic barley grain overexpressing thioredoxin shows evidence that the starchy endosperm communicates with the embryo and the aleurone. Proc. Natl. Acad. Sci. U. S. A. 99: 1632516330.

Wu JH, Ma Z, Hu Y, Zhang H, et al. (2010). Expression of special genes inhibited by powdery mildew (Blumeria graminis f. sp. tritici) in wheat germplasm N9436. Front. Agric. China 4: 10-17.

Yan J, Zhang C, Gu M, Bai Z, et al. (2009). The Arabidopsis CORONATINE INSENSITIVE1 protein is a jasmonate receptor. Plant Cell 21: 2220-2236.

Yu XM, Yu XD, Qu ZP, Han QM, et al. (2007). Construction of wheat SSH cDNA library induced by Puccinia striiformis and analysis of expressed sequence tags. Acta Phytopathol. Sin. 37: 50-55.

Zeng XQ, Wang CY, Ali M, Zhang H, et al. (2010). Profiling gene expression patterns of stripe rust (Puccinia striiformis f. sp. tritici) resistance gene in new wheat germplasm. Pak. J. Bot. 42: 4253-4266.

Zhao S and Qi X (2008). Signaling in plant disease resistance and symbiosis. J. Integr. Plant Biol. 50: 799-807. 